\title{
Picture Books: Puzzles And Possibilities
}

\author{
Margo Pickworth \\ Teacher Librarian \\ Macarthur Anglican School \\ NSW, AUSTRALIA
}

\begin{abstract}
This professional paper deals with the avenue provided by some recent Australian picture books for competent readers to examine the concept of story as well as their own internal and external worlds. Readers were encouraged to 'unlock' the puzzles presented in the books by Matt Ottley, Shaun Tan and Graeme Base. The illustrations were examined in terms of the techniques they used to relate their stories, including the visual images, meaning and symbolism. Personal journals provided an insight into how students related these experiences to their external world of mass media and advertising. Personal relationships, attitudes and feelings were also documented. It is felt that such literature provides endless opportunities for reflection on story and personal growth.
\end{abstract}

\section{Introduction}

Traditionally, picture books as a literary form in western culture come with a variety of assumptions - they are usually large, colourful and easy to read. Their texts are often short and simple, seeming to suggest they are ideally suited to younger readers. However some recent Australian picture books present endless possibilities for "showing and telling, a window for learning to 'read' in a broad sense, exploring relationships between words, pietures and the world we experience every day," (Tan, 2003, personal communication) and should not be confined to the beginner reader.

Inspired by a recent exhibition of picture book art and the publication of some challenging Australian picture books, units of work were planned for students at Macarthur Anglican School. It was the intention to develop the understanding of 'story', incorporating skills of a critical visual literacy. During the planning, implementation and evaluation stages there were many puzzles to be solved and decisions to be selected from endless possibilities.

This presentation will commence with a brief history of Australian picture books, focussing particularly on a number of contemporary illustrators who are providing thoughtful and challenging picture books for older readers. Focus will also be on the importance of visual literacy and identifying valuable learning opportunities presented by such picture books. Several theoretical possibilities have been combined to select the background for the teaching units. A brief outline of the relevant outcomes as well as teaching and learning activities will be included. The results as well as future possibilities will also be considered.

\section{Australian picture books}

Illustrated books in Australia date back to the 1890s and were then only designed for the drawing room where children could look under adult supervision. This trend continued 
until 1930 with the release of Ida Rentoul Outhwaite's lavishly illustrated books that charmed both children and adults alike.

Ida Rentoul and other illustrators emerging in the late nineteenth century were strongly influenced by the Art Nouveau movement. The best-known illustrators of the time included Norman Lindsay, May Gibbs and Dorothy Wall. Norman Lindsay's clever and humorous story about a 'cut and come again puddin' is considered a classic, setting a benchmark for Australian children's literature. His use of bold line and white space focused the humour and personalities that make up this wonderful tale. May Gibbs's Sinugglepot and Cuddlepie, also a classic, romanticised and humanised the nature of the Australian bush with her cute gumnut babies, bad banksia men and a collection of other notorious bush creatures.

The first 'modern' Australian picture book appeared in 1970 with the release of Desmond Digby's Waltzing Matilda. This began a trend of publishing pieture versions of Australian ballads such as the Man firom Ironbark, The Wild Colonial Boy and Mulga Bill's Bicycle. These books celebrated Australia's bushranging past and presented a view of Australian colonial identity. Other books published in the 1980s explored what it meant to be Australian, including Possum Magic, which featured a smorgasbord of Aussie food and Aussic icons. In contrast My. Place published in time for Australia's bicentenary 1988, began to acknowledge multicultural and indigenous citizens. Concurrently, Aboriginal artist Dick Roughsey and his (white) partner were creating fine picture books based on Aboriginal Dreaming stories such as The Reinhow Serpent and The Quinkins.

Whereas the early picture books looked to the past and employed idealised notions of a predominantly white Anglo-Celtic society, increasingly Australian picture books have begun to reflect the complex and culturally diverse world in which children live. They have become increasingly representative of every aspect of contemporary society - concerned with ethnicity, gender, disability and difference of every kind. Their themes reach into areas of social and environmental concern - homeless youth, endangered wildlife, nuclear disaster and bereavement. A growing number of books also relate experiences and celebrate the identities of indigenous and ethnic peoples living in Australia.

Advanced printing techniques, bolder approaches to subject matter and artistic interpretation have also been responsible for more inventive forms of picture books over the recent years. Boundaries are being continually stretched in new styles, media and techniques. With the advances in printing technology the scope for creative use and design has broadened, giving illustrators of picture books a wider range than in the early days of children's book publishing in Australia. Contemporary picture books are providing a chronicle of life in modern society, imaginative interpretations of things past and creative speculations about things to come. "The illustrator's role has changed from that of a decorative artist to a visual narrator." (Mallan, 1999, p.16)

Recently, features of postmodernism have become evident in some contemporary picture books, disrupting the reader and viewer expectations about style, layout, format and the coherence between image and text. They challenge established assumptions of plot, theme and order. Post-modern picture books tackle diverse issues and encourage other ways to read and view, often highlighting parody, play and inter-textuality.

With challenging subject matter of social and cultural diversity, sophistication of design and a wide variety of individual artistic styles, readers are now engaged with a genre which is not only enjoyable but demands different kinds of reading practices (Mallan, 1999). 
In such books the illustrations and text offer multiple ways of reading, meaning making and responding. It is for these reasons that such contemporary and challenging picture books provide excellent possibilities for developing understanding of the concept of story as well as constructing meaning to internal and external worlds.

\section{Australian illustrators}

A strong inspiration for my picture book units of work was an exhibition at the National Maritime Museum. It featured original works by well-known Australian illustrators of Australian books. The pictures were displayed alongside the books from which they came, to give visitors the sense of scale and demonstrating how the original images were transferred to the book. Visitors were able to view the artworks, read information about the illustrators and learn about how artists work in different media. Included in the exhibition were Matt Ottley and Shaun Tan. Graeme Base was also selected as his works can be incorporated into such a study.

\section{Matt Ottley}

Matt Ottley has illustrated a number of picture books for children, including What Faust Saw. Faust's Party, Mrs Millie's Painting and Luke's Way of Looking.

"I believe that writers and illustrators are only now tentatively exploring the potential of the picture book as one of the most powerful modes of expression within our culture of literature" (Ottley, 2002, p. 6). He has acknowledged an interest in the themes and narratives used in the artworks of Vermeers and Picasso, particularly their use of symbolism. This has led to the incorporation of some of these in his picture books. Ottley says, "My feeling is that the extraordinary potential of picture books lies in the depth of subject matter that can be conveyed through the visuals." (Ottley, 2002, p.9)

\section{Graeme Base}

Graeme Base is an illustrator of international fame. His alphabet book Animalia received widespread recognition when first published in 1986. His books are often a clever synthesis of counting books, puzzle books, story and art books. In describing his style of work he indicates that "The basis of my illustration is fantasy but I constantly refer to reality to make the fantasy more convincing." (Base, 2000). His most recent book The Waterhole has a unique style that engages the viewer in the many layers of the story with the essential message of drought and diminishing water supply.

\section{Shaun Tan}

Shaun Tan's picture books have been described as 'strikingly original.' He confesses that his originality is "not the ideas themselves but the way they are put together." The most interesting stories are those "which tell us things that we already know but haven't articulated in our minds" (Tan, 2002, personal communication). The originality stems from combining various ideas from a wide range if sources to produce unexpected results. 
His most widely discussed book The Rahhits deals with the European invasion of Australia and subsequent injustices against the native people. Though the text is simple and sparse, Tan introduces unexpected ideas and extends the metaphorical logic of the text. The cover illustration, based on a nineteenth century painting of Cook's first landing at Botany Bay, provokes an image that is both mysterious and thought-provoking. His other books the Lost Thing and The Red Tree are also challenging both in content and structure.

\section{Visual literacy}

Just as contemporary picture books have changed, so too has our world. Children today live in a visual world. All areas of life confront us with visual images. If images are so pervasive and valued by our culture, it follows that we as a society need to be visually literate and our school systems need to be addressing the issue. Few would dispute that students today need to critically view, comprehend and evaluate non-verbal messages.

Rather than simply reading what is going on, students need a comprehensive metalanguage to articulate the nature of the images they are dealing with. They need to be provided with "tools to read both the text and image in ways that do not necessarily conform to accepted notions that what is presented should actually be accepted on its face value." (Callow, 1997, p.277)

\section{Interpreting picture books}

Research reveals a number of possible frameworks for interpreting picture books. From a strictly visual arts point of view picture books could be analysed along the traditional framework of elements of design - line, direction, shape, size, tone, texture and relationship, as well as the principles of design - contrast, emphasis, harmony, dominance, salience, repetition, pattern, rhythm, and movement.

Callow (1997) states that visual texts are just as complex and difficult to interpret as written texts, perhaps even more so as they are often considered easy and little time is devoted to their understanding. He examined students' past Higher School Certificate (HSC) answers and led to the conclusion that "the lack of technicality clearly limits the depth of analysis that students might make of the images they are asked to comment on." (Callow, 1997. p. 273). He therefore suggested a functional semiotic approach for studying visual texts.

This approach presupposes a variety of meanings about any piece of communication. These meanings can be grouped into three main meta-functions - interpersonal, experiential and textual. Using this meta-language could then equip students and teachers to understand "images as cultural artefacts, products of social processes that can be deconstructed and challenged, not just accepted uncritically." (Callow, 1997, p. 281).

Hart (1999, p. $76-77)$ also suggests a threefold approach to deconstructing visual images. These include the concepts of:

- Field: the subject matter or what is actually happening in an artwork

- Mode: the image as a textual message, its formal composition

- Tenor: the interaction between the image and the viewer. 
Each of these interpretative frameworks appeared valuable for the present examination by students. The puzzle then was whether to adopt one of these approaches or embrace a combination according to the purpose of the study. The approach needed to be useful and relevant to other visual texts both in school and beyond, but simplistic enough to cater for the cognitive, emotional and social needs of the current learners. If the purpose was to develop an understanding of how illustrators construct meaning as well understanding the concept of story, then an inclusive framework should be considered.

A combination of acsthetic awareness as well as critical visual literacy was selected. The overall aim was to encourage students to first look at how the images have been arranged and then the messages that are communicated as a result. This would involve encouraging students to use action-based language to initially describe the content of the images. Speculation on the purpose of this arrangement and how it relates to the text and unfolding story would follow, and then conclude with a personal response.

Three specific aspects were selected for investigation.

- Aesthetic Features such as colour, shape, size and direction, as well as camera angle and viewer position.

- Mood, Characters and Symbolism

- Textual features such as words/ideas portrayed by text, how text is organised and the relationship between picture and text.

Finally, a personal response was included, asking students how these aspects relate to their world - their internal world of thoughts and emotions as well as their external world of relationships with others and their surroundings.

\section{Units of work}

\section{Introduction}

The school in which my units were undertaken is Macarthur Anglican School, located in south-western Sydney. It is an independent school, consisting of two campuses, each with a separate Library. A Teacher Librarian - with both teaching and library qualifications, is employed for four days a week in the Junior School. All classes visit the Library and lessons are planned, taught and evaluated co-operatively with the classroom teacher.

The Junior School library is well stocked with books selected to appeal to ages from 4 -12 years. One of the Collection priorities within the school has been the acquisition of a substantial collection of picture books, particularly for older students. The focus has been on Australian illustrators Shaun Tan, Matt Ottley and Graeme Base. There has been a schoolwide emphasis on the development of visual literacy with a strong interest shown by students and staff for such contemporary literature.

\section{Description}

Several literature units using picture books were designed for eleven and twelve year old competent readers. Students examined these books for the mechanics of visual literacy 
such as how camera angle, viewer position, shape, colour and size are used to construct meaning. Also examined was the use of mood, characters and symbols. Textual features were the third important part of the visual analysis.

At a deeper and more personal level, students also examined their own response to the picture books. They were encouraged to look for experiences they could relate to in their own world, and an extension into the modern world of advertising and mass media. All illustrations were "presented to the reader as a speculative proposition, wrapped in invisible quotation marks, as if to say, "what do you make of this'" (Shaun Tan, 2003 personal communication).

Outcomes and indicators for the units were selected from NSW English Syllabus. Baseline data were gathered through a pre-unit assessment task to gauge each student's level of understanding of the concepts of visual literacy.

During the following weeks, students completed a series of tasks that included

- large group discussions of newspaper photographs

- small group discussions of picture books by selected authors

- individual completion of written tables of details and possible interpretations.

- ongoing collection of relevant printed advertising material

- viewing local advertising billboards

- accessing information about the author from their website.

- participating in visual arts activities using identical terminology, and

- regular completion of a personal Learning Log.

\section{Results}

Results have been based on teacher observation and student's responses. Initial student written responses displayed an awkwardness and unfamiliarity with the language of visual images. The picture books were confusing to the readers and only superficial messages were identified. However during the course of the unit, responses matured and students began to incorporate the visual elements that had been highlighted during class and small group discussions.

Newspaper photographs seemed to provide an excellent medium for discussion, not only for mechanics of visual literacy, but also attempts to analyse the concept of story. Without the influence of colour, the focus shifted to other visual features such as camera angle and viewer position. Students readily engaged in conversation about visual features when the photographs were carefully selected. Sport photos provided many interesting camera angles, while human faces enabled students to conjecture about the 'story' behind the photograph as well as apply visual literacy principles.

Students were readily able to find many real-life examples of visual techniques and apply them to their world of mass media, as advertisements and billboards were critically 'read'. Such techniques as distorted size, use of colour, objects and stereotypes became increasingly obvious to students as we progressed through the unit. Advertisements that 
especially targeted children were shared and deconstructed, with a view to nurturing discriminating viewers.

Symbolism used in picture books proved more difficult for eleven and twelve year old students. Direct explanation was needed to appreciate that often objects are selected in visual images as symbols because we associate them with various ideas and feelings. In Matt Ottley's books the rainbow is a very obvious symbol, as well is the board game in The Red Tree. However were are many other examples of more subtle symbols that were difficult for students to discern.

When considering textual features, students accurately commented on a wide range of relationships. Words and images work together in Matt Ottley's Faust books, while the lack of text makes the visual images more significant in The Waterhole. The impact of physical arrangement of text was observed and its significance to the understanding of the text. In The Red Tree there are several pages when the text appears random and disorganised, reflecting the state of mind of the main character. However, the text in The Lost Thing replicates a student's handwriting, that of the main character, as he re-tells the story in schoolboy rhetoric.

\section{Concept of story}

These picture books also contributed to broadening students' understanding of the narrative or concept of story. Throughout the Learning Logs students were asked to re-tell the story, making comments on whether pictures detract, contribute, confuse, explain, re-tell or provide another layer to the story. They were also asked for their personal reaction to the stories. Students provided a range of thoughtful responses.

While studying Matt Ottley's books, most students observed examples of visual images contributing to the narrative, through its physical arrangement. The text physically leads our eyes to the next implicit part of the story. Graeme Base's Waterhole has a minimum of text and relies heavily on visuals to unfold the narrative. Shaun Tan's illustrations both embellish the text and provide an unusual combination of images that add depth and layers to the story.

Students were familiar with the traditional structure of the narrative including the orientation, complication and resolution and were able to comment on the role of the visuals as the narrative unfolded. Changes in visual messages were witnessed particularly as problems were solved. In The Waterhole, a complete change of colour, camera angle and viewer position is evidenced when rain arrives to fill the Waterhole, in contrast to the everdiminishing and colourless wasteland. In Mrs Millie's Painting students identified the rainbow and the dove as symbols of the resolution of personal fulfilment and harmonious acceptance of each other. Throughout Shaun Tan's book The Red Tree the recurring image of the small red leaf is exchanged for a large red tree as the character resolves her unhappiness.

\section{Personal response}

The Learning Log provided a useful avenue for students to document their personal reaction to the picture books as well as a tool for personal reflection. The selected picture books contained situations to which the students could relate, such as the emotions of fear 
and sadness, feeling out of place and searching for personal satisfaction. Also included were threats to our world including environmental concerns and racial intolerance.

Students identified these situations in their Learning Logs along with personal reactions of fear doubt, hesitation, uncertainty and insecurity. Although, the picture books did not always provide resolution to the world eircumstances, the Learning Log was certainly an avenue for exploring and identifying personal responses.

The Learning Logs also included personal opinion of the stories. While there was a mixture of positive and negative entries, students were encouraged to justify their reactions with evidence from the book itself. The provision of open-ended questions was an effective technique for encouraging purposeful and perceptive written entries in the Learning Log.

\section{Endless possibilities}

This paper described a unit of work designed for young competent readers in which they explored contemporary Australian picture books to develop an understanding of story, while analysing their visual images. Through a variety of learning activities including viewing the texts and other visual images, completing matrixes and maintaining a Learning Log, students were afforded valuable opportunities for reflection on story and personal growth.

\section{References}

Australian National Maritime Museum, (2003). Ocecums of storics. Illustrations from Australian picture books: Teacher resource kit primary. Sydney.

Basce, (i. (2004). Ilis Books. Retrieved March, 13, 2004 from http: Www.penguinputnam.com/Author/AuthorPage $0,00000001552,000 . h(m 1$ ? id 00000

Base, (i. (2001). The waterhole. Ringwood. Victoria. Viking.

Base, (i. (1990). Animalia. Ringwood, Victoria. Penguin.

Brown, 1. (2001). Art education, constructivism and visual literacy: an argument for renewed partnerships. Ant Edrucation. 24: 2,27 29).

(allow. J. \& Unsworth. L. (1997). Equity in the Videosphere. Somthern Re'view; 30(3): 268286.

Callow, J. (Ed.) (1999). Image Maners. NSW Australia: Primary English Teachers Association.

Hart, P. ( (999). The practised eye: ways of secing in visual arts. In J. (allow, (1.d.), Image Matfers. (pp.75-8.3) NSW Australia: Primary English Teachers Association.

Mallan, K. (1999). Reading beneath the surface: using picture books to foster a critical aesthetics. The Alustralian . Jonrinal of Lamglage' and Literacy. 22: 2. 200 211.

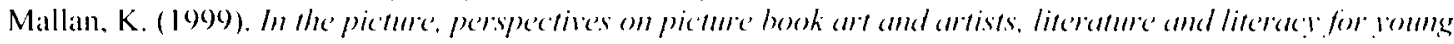
perple. An Australian series: 3. NSW Australia: (entre for Information Studies.

Morrow, R. (1999). The picture book: a unicue art form or good vibes, Orema, July. 3742.

NSW Board (Of Studies (1998). Englis/ K-6 Sy/lahes. NSW Australia: Bourd of Studies NSW.

Ottley, M.(1995). What Fatst sam: Sydncy. NSW. Hodder.

Ottley, M. (1997). Mrs Millie's painting. Sydney, NSW. Hodder.

Ottley. M. (2000). Fanst is part!. Sydney. NSW. Hodder.

Ottley, M. (2001). Luke's way of looking. Sydney. NSW. Hodder.

Ottley, M. (2002). Picture Books: bencath the skin. Scan 21:2.6 13

Patterson. (. (2002). Reading the Pictures, Scom 21:3. 411.

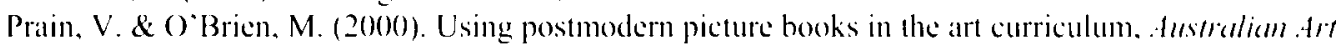
Eiducatiom, 23:2, 2329 .

Quin, R. (1997). Picture this: reading visual language. Cartton, Victoria. Curriculum Corporation.

Spence, B. (2002). The literacy demands of visual text: reading the pictures. Sectm 21:2 +5.

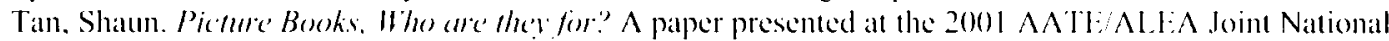
conference. 
Tan. Shaun, Originality amd Creativity a paper presented at the 2001 AATE/ALEA Joint National Conference. Tan, Shaun. (1998). The rahbits. Port Melbourne, Victoria, Lothian.

Tan, Shaun. (2000). The lost thing. Port Melbourne, Victoria, Lothian.

Tan, Shaun. (2001). The red tree Port Melbourne, Vietoria. Lothian.

\section{Author Note}

Margo Pickworth is currently employed as a Teacher Librarian at Macarthur Anglican School, Junior School in south-west Sydney, Australia. During her teaching career she has held a variety of positions including small country schools, pre-schools, TAFE and University. In 1998 she completed a Master of Teacher Librarianship from Charles Sturt University. Currently a committee member of the Australian Schools Library Association, New South Wales, Margo has delivered several conference presentations on the use of the Internet with young children and the Web and Flow process for Teacher Librarians. Her other major professional interest is contemporary Australian picture books for which she has written and implemented many units of work for older readers. 